DOI: https://doi.org/10.24867/12HZ08Vavan

\title{
UVOĐENJE I IMPLEMENTACIJA STANDARDA ISO 14001:2015 SA ASPEKTA UPRAVLJANJA OTPADOM U KOMPANIJI „ELMED“ D.O.O.
}

\section{INTRODUCTION AND IMPLEMENTATION OF ISO 14001:2015 STANDARD FROM AN ASPECT OF WASTE MANAGEMENT COMPANY "ELMED" LLC}

\section{Oblast - INŽENJERSTVO ZAŠTITE ŽIVOTNE} SREDINE

Kratak sadržaj: Ovim radom je prikazana potreba za
uvođenjem standarda ISO 14001:2015, uz sagledavanje
prednosti za samu kompaniju ukoliko primenjuje standard
$i$ pridržava se osnovnih načela životne sredine.
Predstavljena je srž uvođenja standarda sa primenom u
kompaniji "Elmed" d.o.o., kao i šira slika u implemen-
taciji samog standarda i izazovi sa kojima se kompanija
susreće prilikom uvođenja istog. Krajnji rezultat jeste
detaljan plan za implementaciju standarda. Predložena je
$i$ mogućnost za poboljšanje samog standarda u
kompaniju, jer osnovni cilj održavanja svakog standarda
jeste upravo permanentno unapređenje.
\end{abstract}

Verica Vavan, Bojan Batinić, Fakultet tehničkih nauka, Novi Sad kompanija.
Ključne reči: standard ISO 14001:2015, upravljanje otpadom, životna sredina, kompanija "Elmed" d.o.o.

\begin{abstract}
This paper shows the need for the introduction of the ISO 14001:2015 Standard in the company, through which we will see on various examples what are the advantages for the company itself if it applies the standard and adheres to the basic principles of the life environment. It shows the very core of the introduction of standards with the application in the company "Elmed" $L L C$, as well as the wider picture in the implementation of the standard itself and the challenges that the company faces when introducing it. The end result is a detailed plan for the implementation of the standard. The possibility of improving the standard in the company was also suggested, because the basic goal of maintaining each standard is improvement.
\end{abstract}

Keywords: Standard ISO 14001:2015, waste management, life environment, company "Elmed" LLC

\section{UVOD}

Mnoge savremene kompanije, kako bi ocenile sopstveni učinak u očuvanju i zaštiti životne sredine, su se podvrgle sistemima ,provere i preispitivanja“.

Te njihove provere i preispitivanja ne znače nužno da kompanija zadovoljava zakonske regulative i regulative definisane politikom zaštite živorne sredine, kako u datom trenutku tako i dugoročno.

\section{NAPOMENA:}

Ovaj rad proistekao je iz master rada čiji mentor je bio dr Bojan Batinić, vanr.prof..
Kako bi ovo proispitivanje i provere bile što efikasnije neophodno je da se obavlja u okvirima sistema koji su integrisani $\mathrm{u}$ okviru kompanije. Mnogi međunarodni standardi za upravljanje životnom sredinom koji su napravljeni da kompanijama obezbede elemente efektivnog sistema zaštite životne sredine (EMS Envirnonmental Management System) koji se mogu sjediniti sa ostalim upravljačkim zahtevima, kako bi kompanije lakše postigle svoje ciljeve zaštite životne sredine kao i ekonomske ciljeve. Veoma je važno da se ovi međunarodni standardi ne bi trebali koristiti kako bi se stvorile necarinske barijere kao i nametanje raznih zakonskih obaveza, već naprotiv treba da pomažu da se otvore nove tržišne šanse $i$ da se poboljša poslovanje

Svaka savremena kompanija teži što boljoj poziciji na tržištu. Uz dobro organizovan sistem zaštite životne sredine, kompanija može da pokaže održivost svog poslovanja i stekne konkurentnu prednost.

Ovaj međunarodni standard ima za cilj da utvrdi zahteve za sisteme upravljanja zaštitom životne sredine i samim tim da omogući kompaniji razvoj i primenu politike $\mathrm{i}$ ciljeva, uzimajući u obzir zakonske zahteve, kao i informacije u vezi sa značajnim aspektima životne sredine.

Glavni i osnovni cilj standarda ISO 14001:2015 jeste da podstakne prevenciju zagađivanja i zaštitu životne sredine.

\section{POTREBA ZA USPOSTAVLJANJEM SISTEMA UPRAVLJANJA ZAŠTITOM ŽIVOTNE}

Evidentno je da u poslednje vreme raste zaintresovanost društva za očuvanje životne sredine. Strožiji pravilnici i zakoni, ekonomske, tehnološke i druge mere za unapređenje životne sredine koje uključuju i održivi razvoj doveli su do toga da se mnoge kompanije posvete potrebi za efikasnijim sistemom za očuvanje životne sredine. Uvlači se polako u srž poslovne politike kao i kratkoročne i dugoročne ciljeve kompanije.

Svaka kompanija koja je uvela sistem za upravljanje zaštitom životne sredine, pored toga što pozitivno utiče na okruženje, zasigurno postiže bolju tržišnu poziciju i otvara sebi mogućnosti za napredak kako na domaćem tako i na stranom tržištu. 
Veliki broj organizacija je sproveo aktivnosti sa ciljem upravljanja zaštitom životne sredine u skladu sa ISO 14001, počev od identifikacije i praćenja zakonske regulative, identifikacije i vrednovanja aspekata životne sredine, definisanja ciljeva i programa, definisanja načina upravljanja operacija, definisanja načina reagovanja $u$ akcidentnim situacijama, pa sve do praćenja učinka na životnu sredinu [1]. Kako bi se ostvarili ciljevi zaštite životne sredine veoma je važno da se razmotri adekvatna primena tehnologija kojima raspolaže kompanija. Da bi se ostvarili ciljevi zaštite životne sredine, sistem upravljanja zaštitom životne sredine treba da ohrabri organizacije da razmotre primenu najbolje raspoloživih tehnologija. Ove tehnike treba u potpunosti uzeti u obzir u odnosu na troškove i efektivnost, delotvornost i svrsishodnost.

\section{ZAHTEV POSTUPKA PRIMENE SISTEMA UPRAVLJANJA ZAŠTITOM ŽIVOTNE SREDINE - ISO 14001}

Standard ISO 14001 je međunarodni standard koji propisuje zahteve za razvoj sistema menadžmenta zaštite životne sredine (EMS) kako bi organizacija kroz sprovođenje odgovarajućih ciljeva i politika efektivno i efikasno upravljala svim rizicima značajnim za ekološka stanovišta životne sredine. Primenjiv je u svim vrstama poslovnih subjekata, bez obzira na njihovu delatnost, a koji želi uspostaviti, implementirati, održavati i unapređivati EMS. Osnovna namera standarda ISO 14001 je da se na globalnom nivou poboljša poboljša uticaj organizacija i pojedinaca na životnu sredinu.

Primena standarda ISO 14001 sa sobom donosi niz prednosti koje se ne odražavaju samo na stanje životne sredine, već i na samo preduzeće u smislu postizanja većine postavljenih ciljeva [2].

Razvoj sistema menadžmenta zaštite životne sredine usmerava se na postizanje uspeha organizacije, kroz smanjenje potencijalnih rizika zagađenja, manjim otpadom, boljom kontrolom procesa, i uštedom energije. Sve to znači dugoročnu korist kompaniji.

Kompanija mora da uspostavi, dokumentuje, primeni, održava i stalno unapređuje sistem upravljanja zaštitom životne sredine u skladu sa zahtevima stadarda ISO 14001. Kompanija mora da utvrdi i dokumentuje predmet i područje primene sistema upravljanja zaštitom životne sredine.

Svaka organizacija bi trebala da uspostavi, primeni i održava ciljeve zaštite životne sredine za svaku funkciju i za svaki nivo u okviru kompanije. Opšti cilj zaštite životne sredine je sveobuhvatni cilj zaštite životne sredine koji je u skladu sa politikom zaštite životne sredine, a koji organizacija sama sebi postavlja radi ostvarenja. Poseban cilj zaštite životne sredine je detaljan zahtev u pogledu učinka, primenjiv u organizaciji ili njenim delovima, koji proističe iz opštih ciljeva zaštite životne sredine i treba da bude tako postavljen i izvršen da se ti opšti ciljevi postignu [3]. Prilikom identifikacija aktivnosti, usluga i proizvoda, definisanju i preispitivanju opštih i posebnih, ciljeva treba imati u vidu utvrđenu politiku zaštite životne sredine, važeće zakone, značajne aspekte okoline, tehnološke procese kao i finansijske mogućnosti organizacije [4]. Neki od primera opštih ciljeva su: smanjenje nastalog otpada u odnosu na gotov proizvod, jačanje ekološke svesti zaposlenih kao i društvene zajednice, povećanje usklađenosti sa propisima, smanjenje potrošnje vode, i dr. A primeri pojedinačnih ciljeva: smanjenje otpada za $15 \%$ u odnosu na gotov proizvod, smanjenje potrošnje vode za $12 \% \ldots$ Svi programi koji su donešeni za postizanje ciljeva moraju da sardže: aktivnosti, nadzor, odgovornostiza postizanje opštih i posebnih ciljeva za svaku odgovarajuću funkciju i svaki nivo organizacije, i sredstva i vremenski okvir $u$ kojem ovi ciljevi mogu da se postignu.

Zadatak rukovodstva je da obezbedi sve potrebne resurse koji su potrebni za uspostavljanje, primenu, održavanje i unapređenje sistema upravljanja zaštitom životne sredine. Kako bi se olakšalo efikasno upravljanje zaštite životne sredine neophodno je ustanoviti, dokumentovati i saopštiti zadatke, odgovornosti i ovlašćenja. Svaka kompanija je u obavezi da osposobi sve osobe koje obavljaju poslove koji na bilo koji način mogu uticati na životnu sredinu.

U cilju praćenja usaglašenosti sopstvenih aktivnosti sa uspostavljenim sistemom i sa zahtevima standarda, poboljšanja aktivnosti sistema, organizacija mora obezbediti sprovođenje interne provere sistema upravljanja zaštitom životnom sredinom u planiranim intervalima [5].

Sistem internih provera obuhvata: obrazovanje internih proverivača, planiranje, pripremu, proveru, izveštavanje o sprovedenim internim proverama, proveru otklanjanja uočenih neusaglašenosti i njihovo zaključivanje, te izveštavanje i nadzor nad sprovedenim proverama.

Interne provere se sprovode prema godišnjem planu.

\section{VEZA ISO 14001 SA DRUGIM STANDARDIMA}

Zahvaljujući povezanosti između standarda ISO 9001:2015, ISO 14001:2015 i ISO 45001:2018 stvorena je mogućnost integracije ovih menadžment sistema $u$ pogledu njihovog planiranja, uvođenja, održavanja i poboljšavanja.

\section{PRAKSA UVOĐENJA STANDARDA ISO 14001:2015 U INDUSTRIJI}

Rukovodstvo „Elmed“ d.o.o. je donelo odluku za uvođenje sistema upravljanja zaštitom životne sredine, a glavni razlozi su sve strožiji zakonski zahtevi, razvoj ekonomskih i drugih mera za unapređenje zaštite životne sredine i zaštite zdravlja korisnika proizvoda „Elmed“ d.o.o., porast brige zainteresovanih strana, uključujući i održivi razvoj. Poslovnik o integrisanom menadžment sistemu „Elmed“ d.o.o. daje pregled strukture sistema upravljanja zaštitom životne sredine, koji je postavljen i funkcioniše u cilju unapređenja odnosa prema sredini $\mathrm{u}$ kojoj njegovi zaposleni žive i rade [6] .

\section{Upravljanje otpadom u kompaniji „Elmed“ d.o.o. primenom standarda 14001:2015}

Otpad se razvrstava prema katalogu otpada. Katalog otpada predstavlja zbirnu listu otpada prema poreklu njegovog nastajanja. S tim u vezi pravilno upravljanje 
otpadom podrazumeva pre svega identifikaciju i ispitivanje, odnosno klasifikaciju i karakterizaciju otpada. Ispitivanje otpada je metod klasifikacije i karakterizacije otpada u cilju daljeg i što efikasnijeg upravljanja, tretmana ili odlaganja.

Karakterizacija otpada predstavlja postupak ispitivanja kojim se utvrđuju fizičko-hemijske, hemijske i biološke osobine otpada i određuje da li otpad sadrži opasne karakteristike. Karakterizaciju otpada vrši ovlašćena kuća.

Klasifikacija otpada je postupak svrstavanja otpada na jednu ili više lista otpada prema njegovom sastavu, poreklu i daljoj nameni.

Sakupljanje otpada jeste aktivnost sistematskog sakupljanja, razvrstavanja kao i mešanja otpada radi transporta. Nije dozvoljeno mešanje opasnog i neopasnog otpada. Onaj otpad koji je razvrstan prema poreklu i sadržaju se odvojeno sakuplja.

Privremeno skladištenje otpada se vrši na odgovarajućim mestima do momenta odnošenja istog na dalji tretman. Odnošenje otpada na tretman vrše partneri sa kojima je sklopljen ugovor, a samim tim i poseduju Dozvolu za upravljanje otpadom kao i Dozvolu za tarnsport otpada ako je u pitanju opasan otpad.

Kompanija „Elmed“ d.o.o. poseduje Plan upravljanja otpadom sa kojim postupa u skladu sa zakonom [7]. Cilj izrade Plana upravljanja otpadom jeste identifikacija otpadnih materija, koje se javljaju u proizvodnom procesu, kao i analiza uvođenja korektivnih mera u upravljanju otpadom, koje bi mogle rezultirati smanjenjem otpada na izvoru, kao i značajnim uštedama uz poboljšanje rezultata poslovanja i eliminisanje uticaja potencijalno štetnih materija.

\section{Implementacija standarda ISO 14001:2015 u kompaniji „Elmed"d.o.o.}

Prilikom uvođenja standarda ISO 14001:2015 u kompaniji „Elmed“ d.o.o., prva faza se odnosila na formiranje tima koji je vodio proces implementacije. Standard ISO 14001: 2015 sastoji se iz deset ključnih tačaka koje je bilo potrebno implementirati i prilagoditi načinu rada kompanije „Elmed“ d.o.o.. Poštujući zakonske propise, a prateći tačke standarda, kao prva tačka implementacije razvijena je i usvojena Politika IMS.

Osnovna tačka u Politici koja se odnosi na standard ISO 14001:2015 je: „Kompanija se zalaže za posvećenost zaštiti životne sredine, uz održivi razvoj, smanjenje zagađenja i optimalno korišćenje prirodnih resursa.“

\section{REALIZACIJA OPERATIVNIH AKTIVNOSTI}

Planiranje realizacije proizvoda usklađeno je sa zehtevima upravljanja kvalitetom, životnom sredinom i bezbednošću informacija.

Dokumentovane informacije o planu upravljanja realizacijom redovnih aktivnosti se održavaju:

- u planu upravljanja otpadom

- listi analize i vrednovanja rizika zaštite životne sredine
- identifikacija aspekata zaštite životne sredine i upravljanja aspektima.

U slučaju vanrednih situacija u kompaniji „Elmed“ d.o.o. su razvili:

- proceduru postupaka za vanredne situacije,

- plan zaštite od požara

- procedura da osiguranje kontinuiteta bezbednosnih informacija

- procedura u incidentnim situacijama po pitanju bezbednosnih informacija

- pravilnimk za discpilniski postupak

- pravila za rezervna čuvanja kopija informacija i

- procedure za različita istraživanja i testiranja informacija.

\section{PREDLOG MERA ZA POBOLJŠANJE UPRAVLJANJA OTPADOM SA ASPEKTA STANDARDA ISO 14001:2015}

Prilikom uvođenja standarda 14001:2015 u kompaniji "Elmed" d.o.o., IMS tim je odlučio da procesi postupaka, skladištenje i upravljanje opasnim otpadom unapredi i samim tim eliminiše svaki mogući akcident koji može da dovede do narušavanja životne sredine i zdravlja ljudi.

„Elmed“ d.o.o. je prvobitno unapredio prostor za skladištenje opasnog otpada tj. magacin opasnog otpada ugradnjom sistema za nadzor, izolovanjem magacinskog prostora $\mathrm{u}$ odnosu na proizvodni deo kompanije, ali i saradnjom sa odgovornim konsultantskim firmama koje isti transportuju od naše kompanije do mesta za dalju preradu ili postupanje.

Osim magacina opasnog otpada, u magacin hemikalija (mastila i boja) ugrađen je sistem za ventilaciju, kao što je gore beć napomenuto, koji na adekvatan način eliminiše mirise i smanjuje rizik po zdravlje ljudi.

Prilikom odabira kompanije koja će vršiti konsalting, odvoženje i dalje postupanje sa opasnim otpadom IMS tim jje u saradnji sa nabavkom izvršava ocenivanje dobavljača (u ovom slučaju konsultansku kuću je posmatrao kao dobavljača odnosno nekog ko nam nudi svoju uslugu).

Prilikom uvođenja standarda ISO 14001:2015 u kompaniji su pronalizili način da oblast upravljanja otpadom na najjednostavniji ali istovremeno $i$ najefikasniji način uvedu u IMS Poslovnik poštujući zakonske procedure.

Pre uvođenja standarda u kompaniji „Elmed“ d.o.o. praćene su Zakonske procedure i propisi, ali su i razvijeni alati koje sam standard nudi i propisuje, a koji su olakšali praćenje i poštovanje svih mera i propisa iz oblasti upravljanja otpadom i upravljanja hemikalijama $[8,9]$.

\section{ZAKLJUČAK}

Danas društvu nije bitan samo kvalitet proizvoda koji nude kompanije, već i sam uticaj na životnu sredinu koji proizvođač ostvaruje. Uvođenje sistema upravljanja životnom sredinom je jedna od osnovnih stavki za efikasno upravljanje životnom sredinom. Zahvaljujući 
njemu dolazi do velikog unapređenja životne sredine jer omogućava pronalazak najpogodnijih rešenja, povoljnih za sve strane. Standard ISO 14001:2015 mogu implementirati sve kompanije, nezavisno o njihovoj veličini i negativnom uticaju na okolinu.

Na primeru kompanije „Elmed“ d.o.o. uvođenjem standarda ISO 14001:2015 definisano je funkcionisanje sistema upravljanja zažtitiom životne sredine. Kroz posmataranu primenu standarda u kompaniji opisan je sam proces od formiranja tima pa sve do kontinualnog poboljšanja, koji predstavljaju zahteve za ispunjenje posmatranog standarda i čime se omogućava sertifikacija istog.

Ovaj rad može pružiti pomoć kompanijama prilikom uspostavljanja, primene, održavanja i provere sistema upravljanja zažtitom životne sredine. Ovim radom predočeno je zašto je dobro da se uvede standard ISO 14001:2015 u kompanije. Stavljen je akcenat na uspostavljanje sistema zaštite životne sredine u kompanijama. Svaka kompanija koja je uvela sistem za upravljanje zaštitom životne sredine, pored toga što pozitivno utiče na okruženje, zasigurno postiže bolju tržišnu poziciju i otvara sebi mogućnosti za napredak kako na domaćem tako i na stranom tržištu. Razvoj sistema menadžmenta zaštite životne sredine usmerava se na postizanje uspeha organizacije, kroz smanjenje potencijalnih rizika zagađenja, manjim otpadom, boljom kontrolom procesa, i uštedom energije. Sve to znači dugoročnu korist kompaniji.

Tabelarno je prikazana veza između standarda ISO 9001, ISO 14001 i ISO 45001.

Detaljno je opisano uvođenje standarda u kompaniju „Elmed“ d.o.o., kao i realizacija operativnih aktivnosti.

Jedan od glavnih zaključaka je da se smanjenjem rashoda, racionalnijom potrošnjom energenata, smanjenjem negativnih uticaja na okolinu, usavršavanjem zahteva prema standardu ISO 14001, podizanjem ekološke svesti zaposlenih, poboljšava ugled kompanije kao i ugled klijenata.

\section{LITERATURA}

[1] N. Jocić, „Vodič za upravljanje dokumentima i evidencijama“, „ZAŠTITA SISTEMA“ Privredno društvo za izdavačku delatnost i usluge d.o.o. Beograd, 2011 (254)
[2] Boiral, O. (2007): Corporate Greening Through ISO 14001: A Rational Myth?, Organization Science, 18, pp. 127-146

[3] Van Der Veldt, D. (1997): Case studies of ISO 14001: A new business guide for global environmental protection, Environmental Quality Management, 7 (1), pp. $1-19$.

[4] „Elmed“ d.o.o. ISO 14001 Termini i definicije, tačka 3.95

[5] Đuričić R.M. Đuričić M.M, Đuričić M.R., (2011) Savremeni integrisani menadžment sistemi, IR-MIR, Užice

[6] „Elmed“ d.o.o. Poslovnik integrisanog menadžment sistema, 2018.

[7] „Elmed“ d.o.o. Plan upravljanja otpadom, 2019. 2022.

[8] Zakon o hemikalijama (,Službeni glasnik RS“, br. 36/09, 88/10, 92/11, 93/12, 25/2015)

[9] Zakon o upravljanju otpadom (,,Službeni glasnik RS“ br. 36/09, 88/10, 14/16 i 95/2018), član 44.

\section{Kratka biografija}

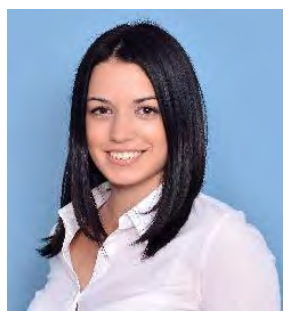

Verica Vavan je rođena 19. novembra 1996. godine u Novom Sadu. Fakultet tehničkih nauka, smer inženjerstvo zaštite životne sredine je upisala 2015 . godine a osnovne akademske studije završila 2019. godine. Master studije upisuje 2019. godine $\mathrm{i}$ iste brani 2020. godine.

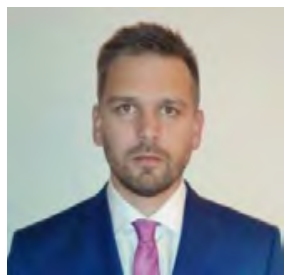

Bojan Batinić (1981) je vanr. prof. na Fakultetu tehničkih nauka „Departmanu za inženjerstvo zaštite životne sredine" u Novom Sadu. Dosadašnji naučno-istraživački rad orijentisan je na analizu fizičko-hemijskih karakteristika komunalnog otpada, modelovanje i projekciju budućih karakteristika otpa$\mathrm{da}$, analizu sistema sakupljanja i transporta otpada, mogućnosti iskorišćenja posebnih tokova otpada i sl. 